\title{
A Comparative Study of Spin Coated Transparent Conducting Thin Films of Gallium and Aluminum Doped ZnO Nanoparticles
}

\author{
A. Alkahlout \\ Department of Physics, Al-Azhar University-Gaza (AUG), P.O. Box 1277, Gaza Strip, State of Palestine \\ Correspondence should be addressed to A. Alkahlout; dramalkahlout@yahoo.com
}

Received 29 May 2015; Revised 25 September 2015; Accepted 18 October 2015

Academic Editor: Anand Pathak

Copyright (C) 2015 A. Alkahlout. This is an open access article distributed under the Creative Commons Attribution License, which permits unrestricted use, distribution, and reproduction in any medium, provided the original work is properly cited.

\begin{abstract}
Transparent conducting Ga: $\mathrm{ZnO}(\mathrm{GZO})$ and $\mathrm{Al}: \mathrm{ZnO}(\mathrm{AZO})$ layers have been deposited by spin coating on glass substrates using crystalline nanoparticles redispersed in 1-propanol. The coatings have been sintered in air at $600^{\circ} \mathrm{C}$ for $15 \mathrm{~min}$ and then postannealed in a reducing atmosphere at $400^{\circ} \mathrm{C}$ for $90 \mathrm{~min}$. The effect of $\mathrm{Ga}$ and $\mathrm{Al}$ doping on the structural, morphological, optical, and electrical properties of the obtained thin films was investigated. Both films were found to be crystalline with a hexagonal structure. A single step spin coated layer $52-56 \mathrm{~nm}$ thick is obtained. To increase the thickness and lower the obtained sheet resistance multilayers coatings have been used. The visible transmission of both layers is high $(T>80 \%)$. The influence of the sintering temperature and the optimum doping concentration was investigated. Five layers synthesized with doping ratio of $1 \mathrm{~mol} . \%$ and sintered at $600^{\circ} \mathrm{C}$ and then submitted to reducing treatment in forming gas exhibited a minimum resistivity value of $7.4 \times 10^{-2} \Omega \cdot \mathrm{cm}$ for GZO layer and $1.45 \Omega \cdot \mathrm{cm}$ for AZO coating.
\end{abstract}

\section{Introduction}

Transparent conducting oxide (TCO) films have been intensively investigated for optical and electrical applications, such as flat-panel displays, liquid crystal displays, organic lightemitting diodes, thin-film transistors, and thin-film solar cells. Indium doped tin oxide $\operatorname{In}_{2} \mathrm{O}_{3}: \mathrm{Sn}$ (ITO) is the most popular TCO. Unfortunately, the application of ITO conducting coating is limited due to high price of indium, thermal instability, lack of corrosion resistance, and poor adhesion of the coating under various environments. Zinc oxide $(\mathrm{ZnO})$ thin films are emerging as the most attractive alternate to ITO because they are inexpensive and nontoxic and have high thermal and chemical stability and a wide energy band gap $(\sim 3.3 \mathrm{eV})$. The substitution of $\mathrm{Zn}^{2+}$ ions with group III ions $\left(\mathrm{B}^{3+}, \mathrm{Al}^{3+}, \mathrm{Ga}^{3+}\right.$, and $\left.\mathrm{In}^{3+}\right)$ generates extra electrons and improves $\mathrm{ZnO}$ optical, electrical, thermal, and magnetic properties. The most common dopant is Aluminum, where $\mathrm{Al}: \mathrm{ZnO}$ (AZO) films exhibit high transparency and low resistivity [1]. The other considered element for use as dopant in $\mathrm{ZnO}$ thin films is Gallium (GZO), which could be the best candidate because of its lower reactivity and greater resistance to oxidation with potentially superior stability when compared to other dopants [2,3]. AZO and GZO films have achieved conductivity approaching those of ITO [4], where AZO films with resistivity $\rho \sim 8.5 \cdot 10^{-5} \Omega \cdot \mathrm{cm}$ were reported by Agura et al. [5]. This value is very close to the resistivity of ITO $\left(7.7 \times 10^{-5} \Omega \cdot \mathrm{cm}\right)$ [6], with a free carrier density of $2.5 \times 10^{21} \mathrm{~cm}^{-3}$.

Such materials are suitable for fabricating transparent electrodes in solar cells, gas sensors, optical waveguides, and micromachined actuators [7]. Several techniques have been employed to obtain AZO and GZO films: pulsed laser deposition, chemical vapor deposition, and sputtering [8]. A resistivity of $\sim 2.8 \times 10^{-4} \Omega \mathrm{cm}$ was achieved for GZO film thickness of $1100 \mathrm{~nm}$ by RF sputtering at room temperature [9]. However, the production cost of sputtering techniques is too high due to its expensive equipment and quite slow deposition rate so other techniques have been used for thin film deposition such as chemical vapor deposition [10], pulsed laser deposition [11], and molecular beam epitaxy [12]. There are few reports about the deposition of AZO and GZO films by wet chemical techniques [13-16].

In this study, gallium and aluminum doped zinc oxide nanopowders (GZO) and (AZO) were synthesized using a 
hydrothermal process with a different doping concentration. The obtained nanopowders were characterized and dispersed in an organic solvent to produce transparent conducting layers on glass substrates. The structural, electrical, and optical properties of the obtained thin films have been studied as a function of doping concentration, thickness, and sintering temperature using X-ray diffraction, scanning electron microscopy, and UV-Visible spectrophotometry measurement.

\section{Materials and Methods}

2.1. Preparation and Characterization of GZO and $A Z O$ Nanoparticles. The AZO and GZO nanopowder were synthesized hydrothermally using the precipitation method. The precursor solution for GZO was prepared by using zinc nitrate hexahydrate reagent grade $\mathrm{Zn}\left(\mathrm{NO}_{3}\right)_{2} \cdot 6 \mathrm{H}_{2} \mathrm{O}$ dissolved in absolute ethanol under stirring at $50^{\circ} \mathrm{C}$ till clear solution was obtained. The used doping precursor is Gallium(III) nitrate hydrate crystalline $\mathrm{Ga}\left(\mathrm{NO}_{3}\right)_{3} \cdot x \mathrm{H}_{2} \mathrm{O}$ dissolved in absolute ethanol. The precursor solution of $\mathrm{AZO}$ was prepared by using zinc acetate dihydrate $\mathrm{Zn}\left(\mathrm{CH}_{3} \mathrm{COO}\right)_{2} \cdot 2 \mathrm{H}_{2} \mathrm{O}$ dissolved in 2-isopropoxy ethanol $\mathrm{C}_{5} \mathrm{H}_{12} \mathrm{O}_{2}$ under stirring at $50^{\circ} \mathrm{C}$ till clear solution was obtained. The doping precursor was Al-isopropoxide $\mathrm{Al}(\mathrm{O}-\mathrm{i}-\mathrm{Pr})_{3}$ dissolved in diethanole amine (DEA) $\mathrm{HN}\left(\mathrm{CH}_{2} \mathrm{CH}_{2} \mathrm{OH}\right)_{2}$. The sol was left under stirring for a few hours. $5 \mathrm{M} \mathrm{NaOH}$ aqueous solution was added dropwise to get a white precipitate. The $\mathrm{pH}$ value was adjusted to 1112. The white precipitate was left under stirring overnight and then treated hydrothermally at $200^{\circ} \mathrm{C}$ for 12 hours. The precipitate was washed with water 4-5 times and dried in air at $100^{\circ} \mathrm{C}$ for 12 hours. Different doping ratios were tested, namely, $0.5,1.0$, and $2.0 \mathrm{~mol} \%$. This was achieved following the same steps as above but with a change of the amount of the added dopant concentration.

The Brunauer-Emmett-Teller (BET) gas adsorption measurement technique was used to measure the surface area of the powders. The powder degassing was achieved by using Autosorb Degasser station, and the measurements were conducted at liquid nitrogen saturation vapor pressure using Autosorb-6B from Quantachrome.

\subsection{Coating Preparation and Characterization}

2.2.1. Coating Solution. The dried material for both GZO and AZO powders is grinded to reduce the size of the agglomerates until a fine powder is obtained (size $<0.2 \mathrm{~mm}$ ). The fine powder was wetted using a small amount of polyethylene glycol $\left(\mathrm{PEG}_{600}\right)$ and 3,6,9-trioxadecanoic acid (TODs) as a dispersing agent. The wetted GZO and AZO powder were dispersed mechanically using a mortar for $15 \mathrm{~min}$. This process breaks the agglomerated powder and produces a homogenous paste. The paste was then dissolved in 1-propanol as a solvent. The obtained suspension was centrifuged at $4000 \mathrm{rpm}$ for $20 \mathrm{~min}$ to remove the remaining large agglomerates.

2.2.2. Film Preparation. A spin coating technique was used to deposit transparent conductive coatings (spin coater model
1001 CPSII from CONVAC). The substrates, low iron borosilicate glass (C-glass), were cleaned in a washing machine using bidistilled water and then heated in an oven at $500^{\circ} \mathrm{C}$ for one hour. Single and multilayer coatings were spun at a speed of $1000 \mathrm{rpm}$ for $15 \mathrm{~s}$. The layers were first dried in air for a few minutes and then sintered for $15 \mathrm{~min}$ at $600^{\circ} \mathrm{C}$. When the effect of sintering temperatures was studied, fused quartz substrates were used in a temperature range of 500 to $700^{\circ} \mathrm{C}$. The thickness and refractive index of the layers were measured by the ellipsometry technique (Spectroscopic Ellipsometer M-2000, J.A. Woollam Co., Inc.).

2.2.3. Film Characterization. X-ray diffraction (XRD) patterns of the layers were collected on XPERT-PRO-MPD (PANalytical) diffractometer unit, using $\mathrm{Cu}$ anode material operating at $40 \mathrm{kV}$ and $30 \mathrm{~mA}$ with wavelength $(\mathrm{K} \alpha$ : $1.541837 \AA, K \beta: 1.392220 \AA$ ). The surface morphology of the coatings was imaged using a high resolution scanning electron microscopy HR-SEM (JSM67500F, JEOL) with secondary electron signal excited by a $10 \mathrm{keV}$ primary beam. The sheet resistance $R_{\square}$ of the films was measured using the four-point probe technique (34401A Multimeter, HEWLETT PACKARD). Transmission and absorption of the coating were measured using a UV-VIS spectrophotometer (CARY 5000 from Varian). The measurements were carried out in the spectral range $300-3000 \mathrm{~nm}$.

\section{Results and Discussion}

3.1. Thermal Properties of the Paste. In order to better understand the thermal behavior of the as-synthesized coating and to ensure the removal of the organic species of the paste, a differential thermal analysis and thermal gravimetry (DTA/TG) spectra were obtained for the GZO (a) and AZO (b) paste doping ratio of 1 mol.\% prepared by wetting nanoparticles in PEG and TODs and then dissolving them in 1-propanol (see Figure 1). The spectra of both pastes have the same features. A very small endothermic peak is observed at temperature below $150^{\circ} \mathrm{C}$. It is accompanied by a mass loss of about $6.2 \mathrm{wt} . \%$ and $5.83 \mathrm{wt} . \%$ for the GZO and AZO paste, respectively. This peak corresponds to the evaporation of the water minorities in the paste. The main feature of the DTA curve is a strong exothermic peak between 250 and $450^{\circ} \mathrm{C}$ with a maximum at $367.5^{\circ} \mathrm{C}$. This feature is accompanied by the main mass loss of about $44.6 \mathrm{wt} . \%$ for the GZO paste and 38.24 wt.\% for the AZO. It may correspond to the degradation and consumption of the organic ligands used in dispersing the particles. For both pastes, no further changes are observed at temperature higher than $500^{\circ} \mathrm{C}$, so no phase transformation is expected by heating the films at a temperature greater than $500^{\circ} \mathrm{C}$.

\subsection{Layer Structure and Morphology}

3.2.1. Layer Structure. Figure 2 shows the XRD patterns of triple GZO and AZO layers with a doping ratio of $1 \mathrm{~mol} \%$ deposited on a borosilicate glass substrate and sintered in air at $600^{\circ} \mathrm{C}$. According to XRD patterns, zincite $\mathrm{ZnO}$ (wurtzite hexagonal structure, pdf number 01-074-9940) is 


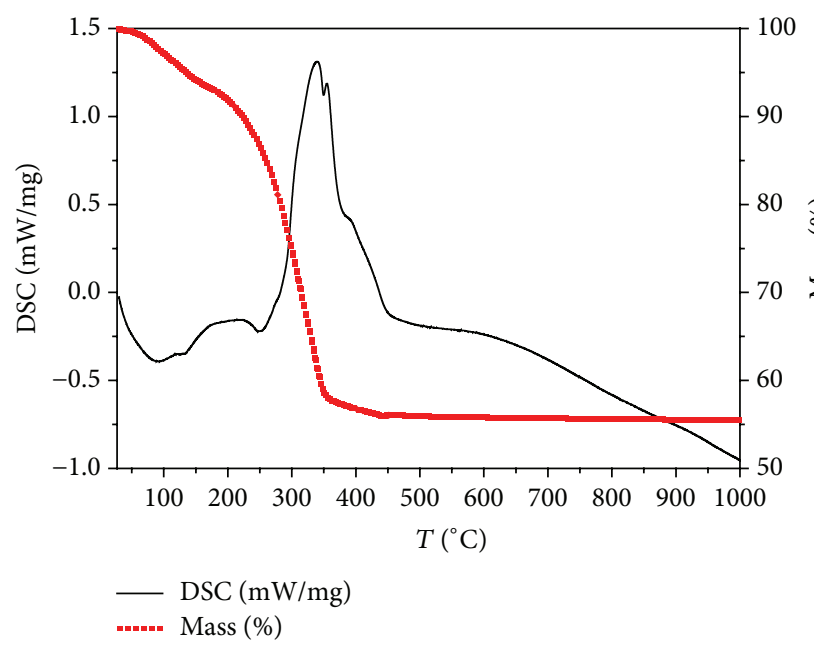

(a)

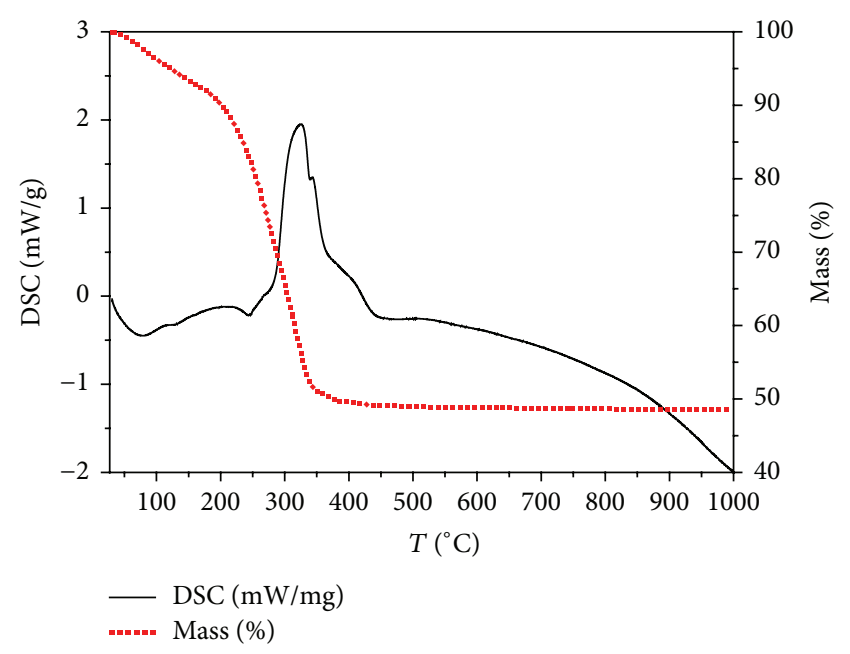

(b)

FIGURE 1: TG and DTA for GZO (a) and AZO (b) pastes with doping ratio of 1 mol.\% prepared by wetting nanoparticles in PEG and TODs then dissolving in 1-propanol.

TABLE 1: Crystallite size and lattice dimensions of GZO and AZO layers.

\begin{tabular}{lcccccccc}
\hline Coating & Phase name & \multicolumn{3}{c}{$\begin{array}{c}\text { Crystallite size }(\mathrm{nm}) \\
(100)(002)(101) \text { mean value }\end{array}$} & $a(\AA)$ & $c(\AA)$ & $(101) /(002)$ \\
\hline AZO & Zincite & 28 & 36 & 26 & 30 & 3.250360 & 5.209163 \\
GZO & Zincite & 38 & 57 & 40 & 45 & 3.248412 & 5.205542 \\
\hline
\end{tabular}

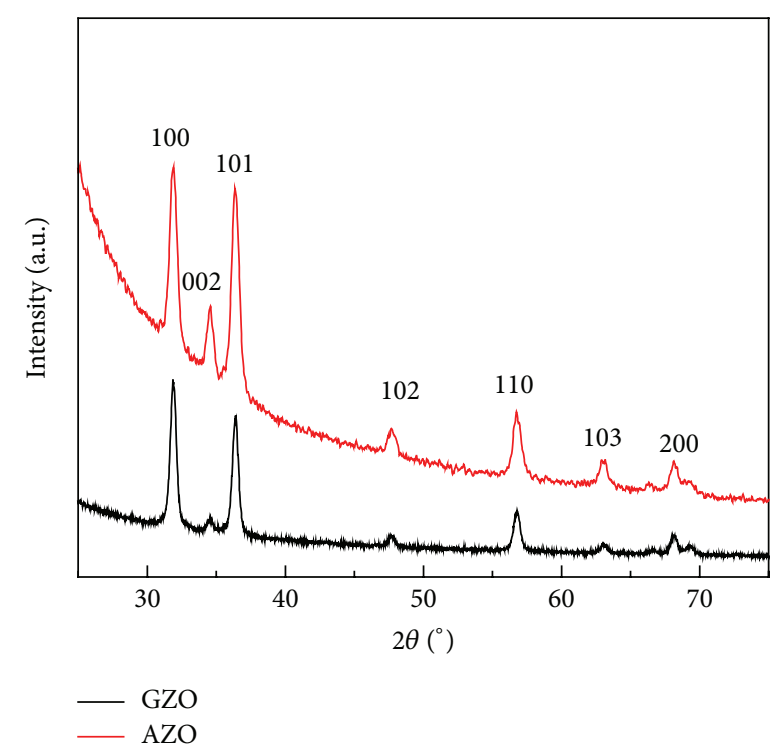

FIGURE 2: XRD pattern of spin coated GZO and AZO layers (doping ratio of $1 \mathrm{~mol} . \%$ ) deposited on borosilicate glass and sintered in air at $600^{\circ} \mathrm{C}$

the only detected crystallographic phase for both coatings. The crystallite size calculated from the (100), (002), and (101) peaks and the lattice dimensions are shown in Table 1. No peak shift was observed between the two layers. The GZO layer exhibited a larger crystallite size $(45 \mathrm{~nm})$ than AZO layer $(30 \mathrm{~nm})$. The full width at the half maximum of $(100)$ peak was found to be $0.5^{\circ}$ for the GZO layer and $0.7^{\circ}$ for the AZO layer, which reveals that the former has a better crystallization degree. This may be attributed to the fact that the difference between the ionic size of $\mathrm{Zn}^{2+}(0.074 \mathrm{~nm})$ and $\mathrm{Ga}^{3+}(0.062 \mathrm{~nm})$ is less than the difference between it and $\mathrm{Al}^{3+}(0.054 \mathrm{~nm})$. Thus, $\mathrm{Ga}$ ions have a lower influence on the $\mathrm{ZnO}$ crystallite than $\mathrm{Al}$ ions [17].

The intensity ratio of $(101) /(002)$ for both layers is higher than unity, but its value for the GZO layer (2.67) is higher than that of the AZO (1.65). This shows that both layers do not have a preferred growth along the (002) plane (c-axis), unlike many reported $\mathrm{ZnO}$ based thin films [18-20]. The higher the $c$-axis preferred orientation the lower the electrical resistivity due to the reduction in the scattering of the carriers at the grain boundaries [21].

3.2.2. Surface Morphology. The morphological and structural features of GZO (a) and AZO (b) coatings with a doping ratio of $1 \mathrm{~mol} . \%$ sintered in air at $600^{\circ} \mathrm{C}$ are shown in Figure 3. Both films consist of loosely packed granular nanocrystalline grains with sizes ranging from 20 to $40 \mathrm{~nm}$. No cracks are seen through the films surfaces. The films have a porous morphology due to evaporation of the solvent and dispersion agent during the heating process. The GZO layer has a homogenous denser structure compared with the AZO layer, which consists of spherical particles dispersed and well separated from each other on the substrate. The dense structure of the conducting layer is favorable for easy 


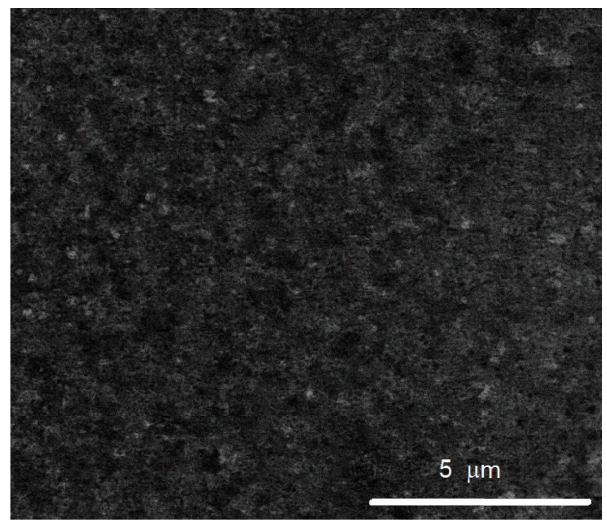

(a)

FIGURE 3: SEM images of the surface morphology of spin coated GZO $1 \mathrm{~mol} \%$.

transport of the charge carriers. This result explains the decrease in conductivity of the AZO layer relative to the GZO one (see Section 3.3). The same structures with an average grain size of $62 \mathrm{~nm}$ was reported for the GZO with 2 at. \% Ga prepared by spray pyrolysis [20].

Many structures have been reported for $\mathrm{ZnO}$ based layers. $\mathrm{ZnO}$ whiskers and acicular particles were prepared by hydrothermal method $[22,23]$ and crystalline nanowires were prepared via low-temperature solution synthesis [24].

3.3. Electrical and Optical Properties. The electrical conductivity of gallium and aluminum-doped zinc oxide (GZO and AZO) films was characterized as a function of doping ratio, thickness of the coatings, and sintering temperature. Figure 4 shows the electrical resistivity, $\rho$, of 5 spin coated GZO and AZO layers as a function of the doping ratio in the nanoparticles used in coating sol. The layers were sintered in air at $600^{\circ} \mathrm{C}$ and then postannealed in forming gas $\left(\mathrm{N}_{2}: \mathrm{H}_{2}=92: 8\right)$ at $400^{\circ} \mathrm{C}$ for $90 \mathrm{~min}$. The $\mathrm{Ga}$ and $\mathrm{Al}$ doping concentration range from 0 to $2 \mathrm{~mol} \%$. As seen in the figure, the GZO layer exhibited lower electrical resistivity compared with the AZO layer deposited at the same conditions where its resistivity is lower by a factor of 30 at the doping ratio of 1 mol.\%. Doping $\mathrm{ZnO}$ with $\mathrm{Al}$ and $\mathrm{Ga}$ resulted first in a sharp decrease of the resistivity of the film, $\rho$, which started to increase by further increase of the doping ratio. At the doping ratio of $1 \mathrm{~mol} . \%$, the resistivity reached a minimum value of $7.4 \times 10^{-2} \Omega \cdot \mathrm{cm}$ and $1.45 \Omega \cdot \mathrm{cm}$ for the GZO and AZO coating, respectively. The resistivity of GZO increased sharply by increasing the doping ratio to reach $1.06 \Omega \cdot \mathrm{cm}(14$ times the value at $1 \mathrm{~mol} . \%)$ while the resistivity of the AZO layer increased to $2.24 \Omega \cdot \mathrm{cm}(1.5$ times the value at $1 \mathrm{~mol} . \%)$. The improvement in electrical conductivity by introducing $\mathrm{Ga}$ and $\mathrm{Al}$ in the coating is due to the increase in the free electron density. The substitution of $\mathrm{Al}^{3+}$ or $\mathrm{Ga}^{3+}$ ion for $\mathrm{Zn}^{2+}$ ion releases one free electron in the lattice contributing to the electrical conductivity. At the high doping concentration, the free electron density begins to decrease because an increasing number of dopant atoms form neutral defects instead of

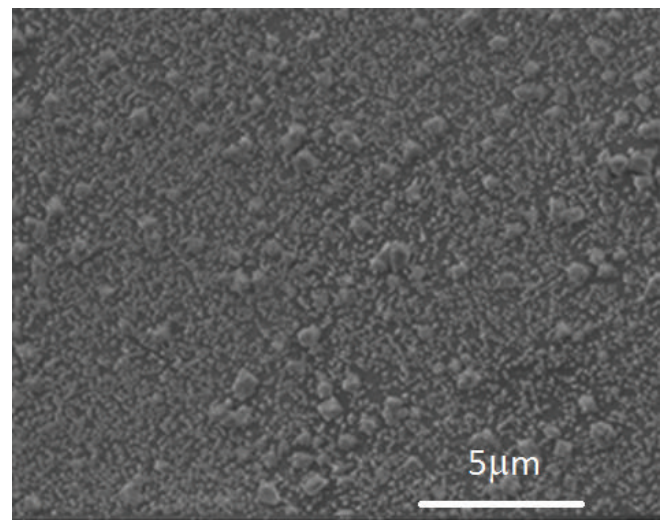

(b)

(a) and AZO (b) sintered at $600^{\circ} \mathrm{C}$. Both layers have doping ratio of

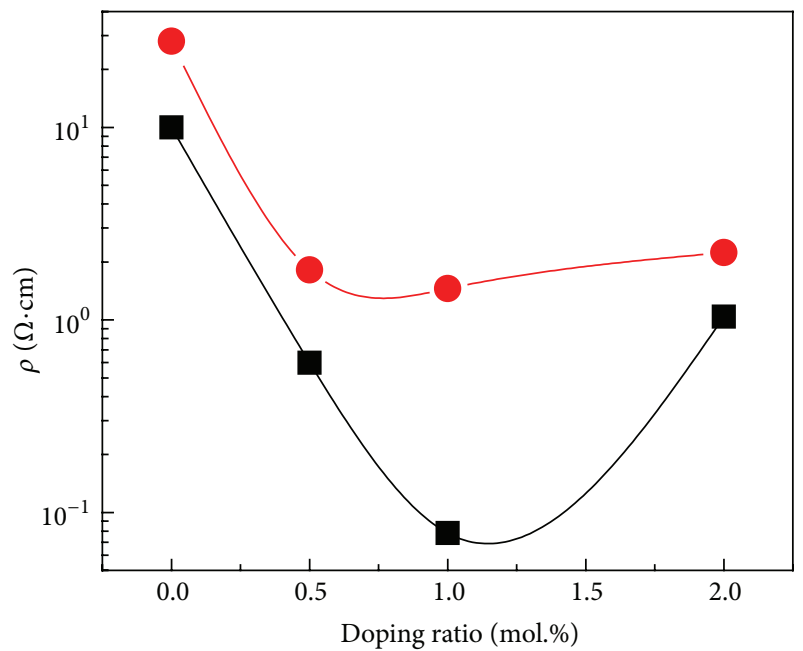

- GZO

FIGURE 4: The electrical resistivity, $\rho$, of spin coated $5 \mathrm{GZO}$ and AZO layers as a function of doping ratio in the dispersed nanopowders; the layers were sintered at $600^{\circ} \mathrm{C}$ in air and then heated at $400^{\circ} \mathrm{C}$ for $90 \mathrm{~min}$ in reducing gas.

substituting the $\mathrm{Zn}$ ions, and these neutralized atoms do not contribute free electrons, being located at the interstitials, acting as defects, reducing the film quality and increasing scattering [25]. It was reported also that the mobility and hence the resistivity of transparent conductive oxides are limited by ionized impurity scattering for high carrier concentrations [26]. An optimal doping concentration, which leads to the highest carrier concentration and lowest electrical resistivity, exists there. Chen [27] found that the highest Hall mobility of the GZO films is $5.97 \mathrm{~cm}^{2} / \mathrm{V} \cdot \mathrm{s}$ at carrier concentration of $1.05 \times 10^{21} \mathrm{~cm}^{-3}$.

The crystallite size was calculated from the XRD spectrum of the GZO and AZO nanopowder having different 


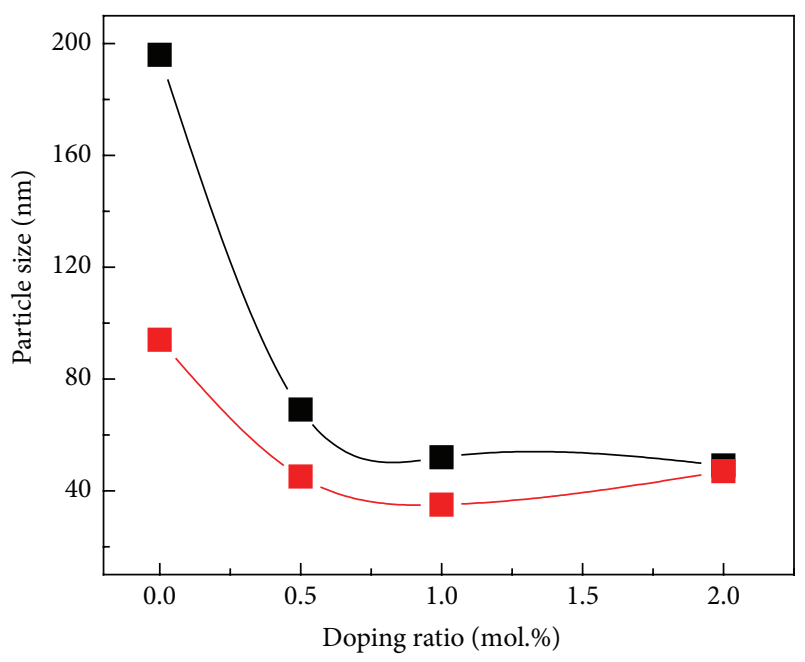

FIGURE 5: Particles sizes of GZO and AZO powder synthesized hydrothermally with different doping ratio.

doping ratios (see Figure 5). Doping $\mathrm{ZnO}$ with $\mathrm{Ga}$ or $\mathrm{Al}$ decreased the crystallite size due to the smaller ionic radius of the dopant when compared to $\mathrm{Zn}$. Beside that, the covalent bond lengths of $\mathrm{Ga}-\mathrm{O}$ and $\mathrm{Zn}-\mathrm{O}$ are estimated to be $1.92 \AA$ and $1.97 \AA$, respectively [28].

Further increase of the doping ratio above 1 mol.\% seems to promote the crystallite growth of AZO nanoparticles where the particle size increased to $47 \mathrm{~nm}$ at a doping ratio of 2 mol.\%. This seems to be caused by exceeding the thermodynamic limitation of solubility of $\mathrm{Al}$ in $\mathrm{ZnO}$ [29], resulting in a clustering of the dopant ions, which significantly increases the scattering rate. It could also produce a nonparabolicity of the conduction band, which has to be taken into account for degenerately doped semiconductors with filled conduction bands. This is in agreement with the Burstein-Moss effect, pointing to the increase of band gap by escalating doping ratio (charge carrier) [30].

The lower resistivity of the GZO layer compared to the AZO might refer to the high scattering at the boundaries in the AZO layer where XRD pattern of nanoparticles showed that it has smaller grains. It is well known that the scattering at grain boundaries has a great effect on the conductivity and the charge mobility. The same result was reported in the comparative study made by [31] for GZO and AZO sol gel films.

Aegerter et al. [32] reported that the resistivity of transparent conducting coating decreases with the number of layers and that the coatings become denser. The dense structure of the conducting layer is favorable for easy transport of the charge carriers. It is difficult to produce single layer with reasonable thickness, therefore, multiple coating processes are required. To obtain thicker films, multilayers coatings were deposited by repeating the coating steps (spinning and sintering). Figure 6 shows the variation of the sheet resistance and transmittance at $\lambda=550 \mathrm{~nm}$ with the thickness of layers. Increasing the thickness of the films improves the electrical conductivity but has a negative impact on their optical properties. For GZO layer (Figure 6(a)), the sheet resistance decreased from $25 \mathrm{k} \Omega \square$ for $53 \mathrm{~nm}$ thick single layer to $2.8 \mathrm{k} \Omega \square$ for $368 \mathrm{~nm}$ thick 5-layer coating. On the other hand, the optical transmission dropped from 93 to $86 \%$. In general, the film with triple layers ( $159 \mathrm{~nm}$ thick) is found to have a good optical quality $(T=89 \%)$ and a moderate electrical sheet resistance $\left(R_{\square}=4.3 \mathrm{k} \Omega \square\right)$. A sheet resistance of $3.3 \mathrm{k} \Omega \square$ was reported for the GZO thin film doped with $1.5 \mathrm{~mol} . \%$ of $\mathrm{Ga}$ after postannealing at $650^{\circ} \mathrm{C}$ for $60 \mathrm{~min}$ in air for sol-gel spin coated $150 \mathrm{~nm}$ thick layers [31].

As seen in Figure 6(b), the single AZO layer is approximately $56 \mathrm{~nm}$ thick and has a sheet resistance of $760 \mathrm{k} \Omega \square$ $(\rho=3.7 \Omega \cdot \mathrm{cm})$ and an optical transmission of $90 \%$. The deposition of multilayers improves the electrical properties where the sheet resistance of a 3-layer coating is $104 \mathrm{k} \Omega \square$, a factor of about 7.3 lower $(\rho=1.74 \Omega \cdot \mathrm{cm})$.

Fortunato et al. [33] found that for sputtered layers that are up to approximately $400 \mathrm{~nm}$ the film properties are highly dependent on the surface (two-dimensional behavior), while for thicker films $R$ is clearly dependent on the bulk properties of the material (three-dimensional behavior).

The optical properties of GZO and AZO layers were studied by UV-Vis spectrophotometer. Figure 7(a) shows the transmittance of a single GZO and AZO film made with a doping ratio of $1 \mathrm{~mol} . \%$, sintered in air at $600^{\circ} \mathrm{C}$, and postannealed in forming gas at $400^{\circ} \mathrm{C}$. Both coatings exhibit a high transmittance in the visible range $(\lambda=400-700 \mathrm{~nm})$, close to $90 \%$, and a little lower transmission in the near IR range due to the free charge carrier absorption. The absorption edge of the spectra is shifted to a higher energy (blue shift) for the AZO layer compared with the GZO one. The energy band gap $\left(E_{g}\right)$ values can be obtained from the absorption coefficient $\alpha$, which can be calculated as a function of the photon energy $(h \nu)$. The relationship between the absorption coefficient and photon energy can be expressed as [34]

$$
(\alpha h \nu)^{2}=C\left(h \nu-E_{g}\right)
$$

where $C$ is a constant and $\alpha$ can be calculated from the expression $\alpha=A / d$, where $A$ is the measured absorbance and $d$ is the thickness of the coating. The $E_{g}$ value can be obtained by extrapolating the linear portion of the graph of $(\alpha h \nu)^{2}$ versus $h v$, which has been shown in Figure 7(b). The obtained $E_{g}$ value for the AZO layer is $4.14 \mathrm{eV}$, which is higher than that of the GZO layer ( $4.01 \mathrm{eV})$. The obtained energy gap for both films is higher than the reported value, $3.3 \mathrm{eV}$, for the bulk $\mathrm{ZnO}$. This blue shift may be attributed to quantum confinement effects. This effect appears as a blue shift of the energy gap in such a way that the smaller the nanoparticles the stronger the blue shift [35], which explains the greater blue shift for the AZO layer compared with the GZO one as it has smaller particles.

The influence of the heat treatment temperature on electrical conductivity of GZO and AZO layers prepared from colloidal solution of GZO and AZO nanoparticles (doping ratio $1 \mathrm{~mol} . \%$ ) in 1-propanol as a solvent was tested in the temperature range $500-700^{\circ} \mathrm{C}$. For the $\mathrm{GZO}$ layer, no significant changes have been noticed by increasing the 


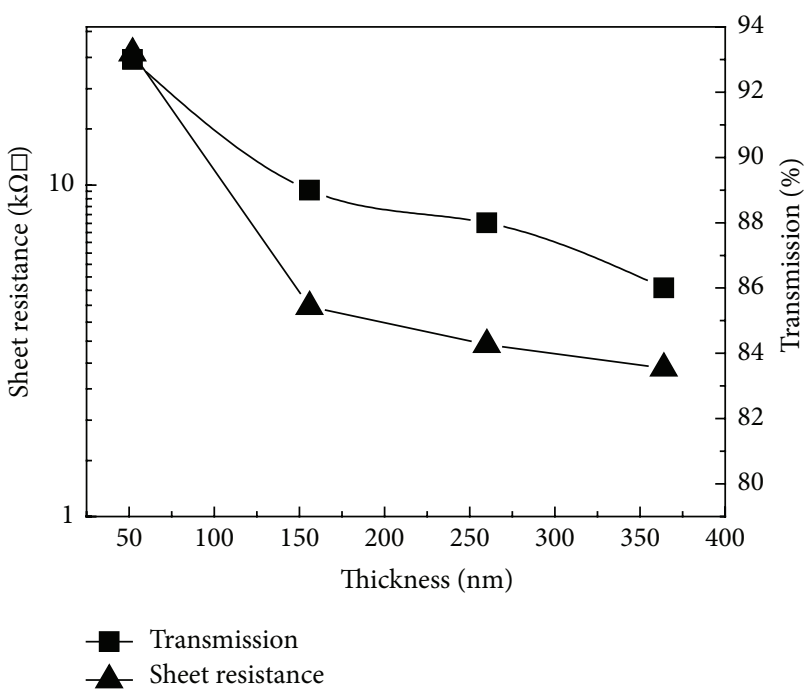

(a)

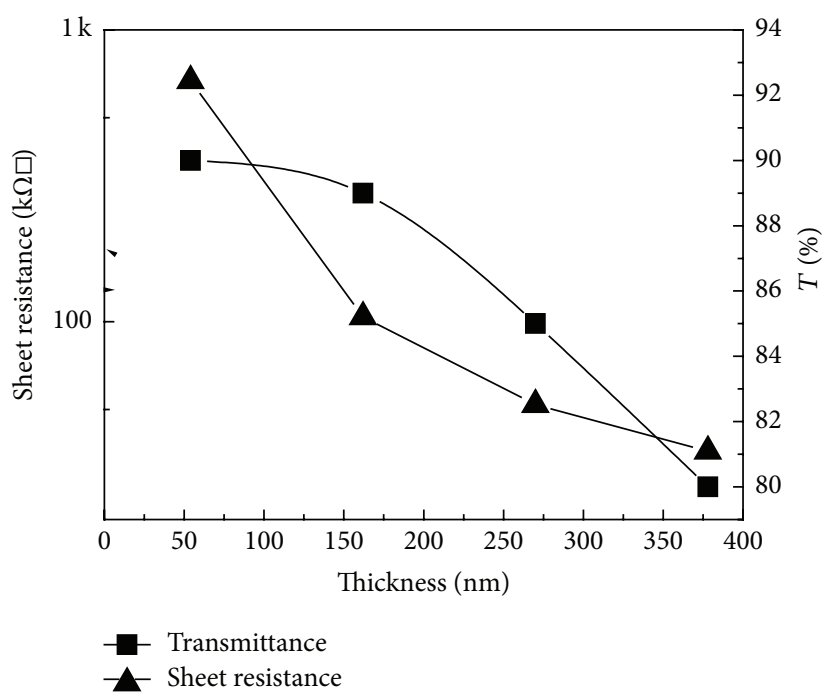

(b)

FIGURE 6: Sheet resistance and optical transmission at $550 \mathrm{~nm}$, of spin coated $\mathrm{GZO}$ (a) and $\mathrm{AZO}$ (b) multilayers, sintered in air at $600^{\circ} \mathrm{C}$ and further postannealed in forming gas at $400^{\circ} \mathrm{C}$, as a function of layer thickness. Each single layer is approximately $52-55 \mathrm{~nm}$ thick.

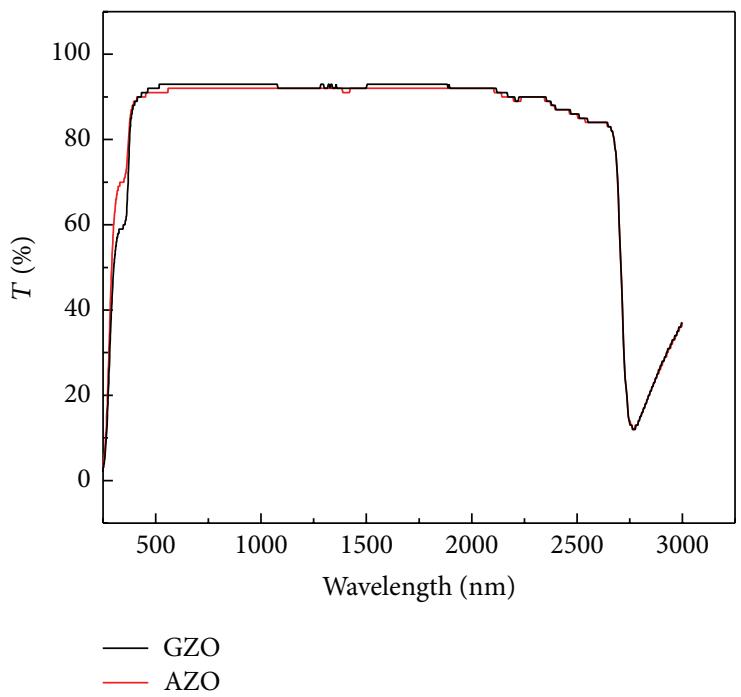

(a)

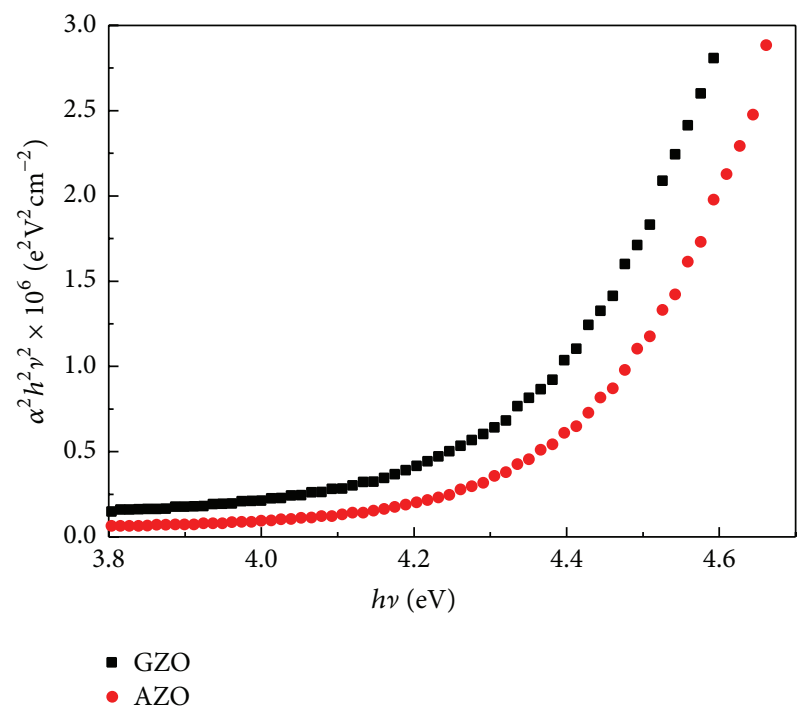

(b)

FIGURE 7: The optical transmittance in the wavelength range 300-3000 $\mathrm{nm}$ (a), $\alpha^{2} h^{2} v^{2}$ versus $h v$ (b) for single GZO and AZO layers sintered in air at $600^{\circ} \mathrm{C}$ and further postannealed in forming gas at $400^{\circ} \mathrm{C}$.

temperature between $500^{\circ} \mathrm{C}$ and $600^{\circ} \mathrm{C}$ where the electrical resistivity decreased from $7.95 \times 10^{-2} \Omega \cdot \mathrm{cm}$ at $500^{\circ} \mathrm{C}$ to reach a minimum value of $7.42 \times 10^{-2} \Omega \cdot \mathrm{cm}$ at $600^{\circ} \mathrm{C}$. On the other hand, the resistivity of the AZO layer is halved by increasing the temperature from $500^{\circ} \mathrm{C}$ to $600^{\circ} \mathrm{C}$ reaching a minimum of $5.2 \Omega \cdot \mathrm{cm}$. However, the resistivity of both layers increased by increasing the sintering temperature above $600^{\circ} \mathrm{C}$ (see Figure 8). The increase of electrical resistivity for layers sintered at temperatures higher than $600^{\circ} \mathrm{C}$ seems to be due to the formation of pores through the film resulting from the decomposition reaction of precursors at high temperatures and the evaporation of residual organics.
In addition, microvoids can then coalesce to form bigger pores. The same phenomena were faced by Kim and Tai [36] for sol gel aluminum doped zinc oxide, AZO. They suggested that the mobility of electrons decreases due to a scattering by $\mathrm{Al}_{2} \mathrm{O}_{3}$ segregating at the grain boundaries.

\section{Conclusion}

Aluminum and gallium doped $\mathrm{ZnO}$ TCO thin films were deposited by spin coating on glass substrates using crystalline nanoparticles redispersed in 1-propanol. All films have a hexagonal wurtzite crystal structure. The particle size and 


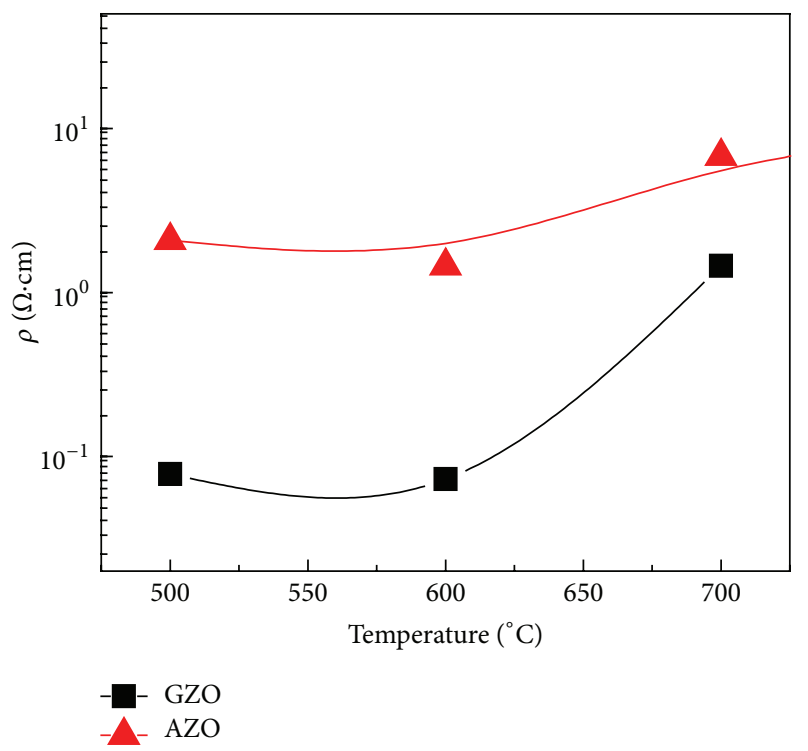

FIGURE 8: Resistivity of GZO and AZO 5 layers with doping ratio of $1 \mathrm{~mol} \%$, deposited on quartz substrate and sintered in air at different temperatures and then postannealed in reducing gas for $90 \mathrm{~min}$ at $400^{\circ} \mathrm{C}$.

electrical and optical properties for both films are found to be dependent on the doping ratio. A minimum sheet resistance was obtained for GZO and AZO films at a doping ratio of $1 \mathrm{~mol} . \%$. The heat treatment has a great effect on the obtained layers where no phase changes were observed at temperature higher than $500^{\circ} \mathrm{C}$, while the electrical conductivity is found to decrease by heating the films at temperature higher than $600^{\circ} \mathrm{C}$. The transmittance of the AZO and GZO thin films is higher than $80 \%$ in the visible region. The optical band gap of the AZO is higher than that of the GZO, and both of them are higher than that of bulk $\mathrm{ZnO}$ in accordance with the Burstein-Moss effect. In conclusion, GZO films showed better properties than AZO ones when used as transparent conducting coatings.

\section{Conflict of Interests}

The author declares that there is no conflict of interests regarding the publication of this paper.

\section{References}

[1] A. Al Kahlout, N. Al Dahoudi, S. Heusing, K. Moh, R. Karos, and P. W. de Oliveira, "Structural, electrical and optical properties of aluminum doped zinc oxide spin coated films made using different coating sols," Nanoscience and Nanotechnology Letters, vol. 6, no. 1, pp. 37-43, 2014.

[2] A. AlKahlout, "A wet chemical preparation of transparent conducting thin films of Ga-doped $\mathrm{ZnO}$ nanoparticles," Journal of Sol-Gel Science and Technology, vol. 67, no. 2, pp. 331-338, 2013.

[3] C.-Y. Tsay, K.-S. Fan, and C.-M. Lei, "Synthesis and characterization of sol-gel derived gallium-doped zinc oxide thin films," Journal of Alloys and Compounds, vol. 512, no. 1, pp. 216-222, 2012.
[4] E. Fortunato, L. Raniero, L. Siva et al., "Highly stable transparent and conducting gallium-doped zinc oxide thin films for photovoltaic applications," Solar Energy Materials and Solar Cells, vol. 92, no. 12, pp. 1605-1610, 2008.

[5] H. Agura, A. Suzuki, T. Matsushita, T. Aoki, and M. Okuda, "Low resistivity transparent conducting Al-doped $\mathrm{ZnO}$ films prepared by pulsed laser deposition," Thin Solid Films, vol. 445, no. 2, pp. 263-267, 2003.

[6] H. Ohta, M. Orita, M. Hirano, H. Tanji, H. Kawazoe, and H. Hosono, "Highly electrically conductive indium-tin-oxide thin films epitaxially grown on yttria-stabilized zirconia (100) by pulsed-laser deposition," Applied Physics Letters, vol. 76, no. 19, pp. 2740-2742, 2000.

[7] P. Jood, R. J. Mehta, Y. Zhang et al., "Al-doped zinc oxide nanocomposites with enhanced thermoelectric properties," Nano Letters, vol. 11, no. 10, pp. 4337-4342, 2011.

[8] S. L. Ou, D. S. Wuu, S. P. Liu, Y. C. Fu, S. C. Huang, and R. H. Horng, "Pulsed laser deposition of ITO/AZO transparent contact layers for GaN LED applications," Optics Express, vol. 19, no. 17, pp. 16244-16251, 2011.

[9] C. Y. Hsu and C. H. Tsang, "Effects of $\mathrm{ZnO}$ buffer layer on the optoelectronic performances of GZO films," Solar Energy Materials and Solar Cells, vol. 5, pp. 530-536, 2008.

[10] Y. Kashiwaba, K. Sugawara, K. Haga, H. Watanabe, B. P. Zhang, and Y. Segawa, "Characteristics of $\mathrm{c}$-axis oriented large grain $\mathrm{ZnO}$ films prepared by low-pressure MO-CVD method," Thin Solid Films, vol. 411, no. 1, pp. 87-90, 2002.

[11] F. Wu, L. Fang, Y. J. Pan, K. Zhou, Q. L. Huang, and C. Y. Kong, "Effect of substrate temperature on the structural, electrical and optical properties of $\mathrm{ZnO}: \mathrm{Ga}$ thin films prepared by $\mathrm{RF}$ magnetron sputtering," Physica E: Low-Dimensional Systems and Nanostructures, vol. 43, no. 1, pp. 228-234, 2010.

[12] J.-I. Nomoto, M. Konagai, K. Okada, T. Ito, T. Miyata, and T. Minami, "Comparative study of resistivity characteristics between transparent conducting AZO and GZO thin films for use at high temperatures," Thin Solid Films, vol. 518, no. 11, pp. 2937-2940, 2010.

[13] H. Kato, M. Sano, K. Miyamoto, and T. Yao, "Growth and characterization of Ga-doped $\mathrm{ZnO}$ layers on a-plane sapphire substrates grown by molecular beam epitaxy," Journal of Crystal Growth, vol. 237-239, part 1, pp. 538-543, 2002.

[14] V. Fathollahi and M. M. Amini, "Sol-gel preparation of highly oriented gallium-doped zinc oxide thin films," Materials Letters, vol. 50, no. 4, pp. 235-239, 2001.

[15] G. K. Paul and S. K. Sen, "Sol-gel preparation, characterization and studies on electrical and thermoelectrical properties of gallium doped zinc oxide films," Materials Letters, vol. 57, no. 3, pp. 742-746, 2002.

[16] K. Y. Cheong, N. Muti, and S. R. Ramanan, "Electrical and optical studies of $\mathrm{ZnO}$ :Ga thin films fabricated via the sol-gel technique," Thin Solid Films, vol. 410, no. 1-2, pp. 142-146, 2002.

[17] R. Al Asmar, S. Juillaguet, M. Ramonda et al., "Fabrication and characterization of high quality undoped and $\mathrm{Ga}_{2} \mathrm{O}_{3}$-doped $\mathrm{ZnO}$ thin films by reactive electron beam co-evaporation technique," Journal of Crystal Growth, vol. 275, no. 3-4, pp. 512520, 2005.

[18] S. E. Park, J. C. Lee, P. K. Song, and J.-H. Lee, "Properties of gallium-doped zinc-oxide films deposited by RF or DC magnetron sputtering with various GZO targets," Journal of the Korean Physical Society, vol. 54, p. 1283, 2009.

[19] P. K. Nayak, J. Yang, J. Kim et al., "Spin-coated Ga-doped ZnO transparent conducting thin films for organic light-emitting 
diodes," Journal of Physics D: Applied Physics, vol. 42, no. 3, Article ID 035102, 2009.

[20] A. R. Babar, P. R. Deshamukh, R. J. Deokate, D. Haranath, C. H. Bhosale, and K. Y. Rajpure, "Gallium doping in transparent conductive $\mathrm{ZnO}$ thin films prepared by chemical spray pyrolysis," Journal of Physics D: Applied Physics, vol. 41, no. 13, Article ID 135404, 6 pages, 2008.

[21] V. Musat, B. Teixeira, E. Fortunato, R. C. C. Monteiro, and P. Vilarinho, "Al-doped ZnO thin films by sol-gel method," Surface and Coatings Technology, vol. 180-181, pp. 659-662, 2004.

[22] C.-H. Lu and C.-H. Yeh, "Influence of hydrothermal conditions on the morphology and particle size of zinc oxide powder," Ceramics International, vol. 26, no. 4, pp. 351-357, 2000.

[23] W.-J. Li, E.-W. Shi, M.-Y. Tian, W.-Z. Zhong, and Z.-W. Yin, "The synthesis of $\mathrm{ZnO}$ acicular particles by the hydrothermal discharging-gas method," Journal of Materials Research, vol. 14, no. 4, pp. 1532-1537, 1999.

[24] L. Goris, R. Noriega, M. Donovan, J. Jokisaari, G. Kusinski, and A. Salleo, "Intrinsic and doped zinc oxide nanowires for transparent electrode fabrication via low-temperature solution synthesis," Journal of Electronic Materials, vol. 38, no. 4, pp. 586595, 2009.

[25] K. Y. Cheong, N. Muti, and S. R. Ramanan, "Electrical and optical studies of $\mathrm{ZnO}: \mathrm{Ga}$ thin films fabricated via the sol-gel technique," Thin Solid Films, vol. 410, no. 1-2, pp. 142-146, 2002.

[26] H.-M. Zhou, D.-Q. Yi, Z.-M. Yu, L.-R. Xiao, and J. Li, "Preparation of aluminum doped zinc oxide films and the study of their microstructure, electrical and optical properties," Thin Solid Films, vol. 515, no. 17, pp. 6909-6914, 2007.

[27] $\mathrm{H}$. Chen, Dye sensistized solar cells using $\mathrm{ZnO}$ nanoyips and $\mathrm{Ga}$ doped $\mathrm{ZnO}$ films [Ph.D. thesis], The State University of New Jersey, New Brunswick, NJ, USA, 2008.

[28] W. J. Park, H. S. Shin, B. D. Ahn et al., "Investigation on doping dependency of solution-processed Ga-doped $\mathrm{ZnO}$ thin film transistor," Applied Physics Letters, vol. 93, no. 8, Article ID 083508, 2008.

[29] J. G. Lu, Z. Z. Ye, Y. J. Zeng et al., "Structural, optical, and electrical properties of $(\mathrm{Zn}, \mathrm{Al}) \mathrm{O}$ films over a wide range of compositions," Journal of Applied Physics, vol. 100, no. 7, Article ID 073714, 2006.

[30] F. K. Shan and Y. S. Yu, "Band gap energy of pure and Al-doped $\mathrm{ZnO}$ thin films," Journal of the European Ceramic Society, vol. 24, no. 6, pp. 1869-1872, 2004.

[31] M.-C. Jun, S.-U. Park, and J.-H. Koh, "Comparative studies of Al-doped $\mathrm{ZnO}$ and $\mathrm{Ga}$-doped $\mathrm{ZnO}$ transparent conducting oxide thin films," Nanoscale Research Letters, vol. 7, article 639, 2012.

[32] M. A. Aegerter, A. Reich, D. Ganz, G. Gasparro, J. Pütz, and T. Krajewski, "Comparative study of $\mathrm{SnO} 2: \mathrm{Sb}$ transparent conducting films produced by various coating and heat treatment techniques," Journal of Non-Crystalline Solids, vol. 218, pp. 123128, 1997.

[33] E. Fortunato, A. Gonçalves, V. Assunção et al., "Growth of $\mathrm{ZnO}$ :Ga thin films at room temperature on polymeric substrates: thickness dependence," Thin Solid Films, vol. 442, no. 12, pp. 121-126, 2003.

[34] S. Maensiri, P. Laokul, and V. Promarak, "Synthesis and optical properties of nanocrystalline $\mathrm{ZnO}$ powders by a simple method using zinc acetate dihydrate and poly(vinyl pyrrolidone)," Journal of Crystal Growth, vol. 289, no. 1, pp. 102-106, 2006.
[35] K. Tarasov and O. Raccurt, "A wet chemical preparation of transparent conducting thin films of Al-doped $\mathrm{ZnO}$ nanoparticles," Journal of Nanoparticle Research, vol. 13, no. 12, pp. 67176724, 2011.

[36] Y.-S. Kim and W.-P. Tai, "Electrical and optical properties of Al-doped $\mathrm{ZnO}$ thin films by sol-gel process," Applied Surface Science, vol. 253, no. 11, pp. 4911-4916, 2007. 

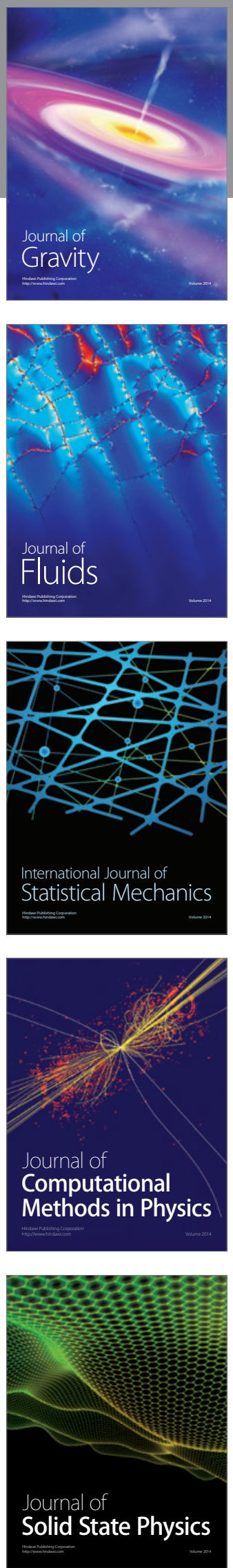

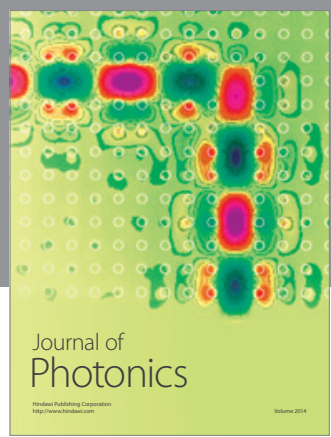

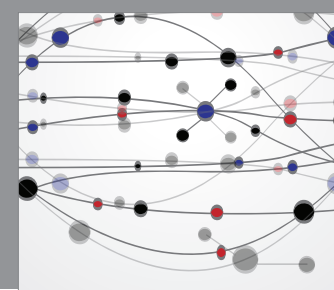

The Scientific World Journal

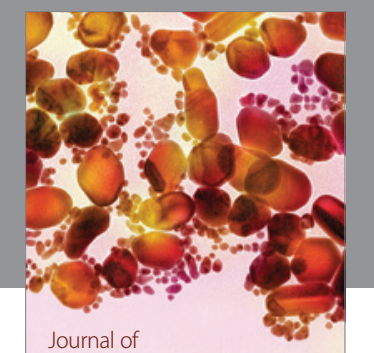

Soft Matter
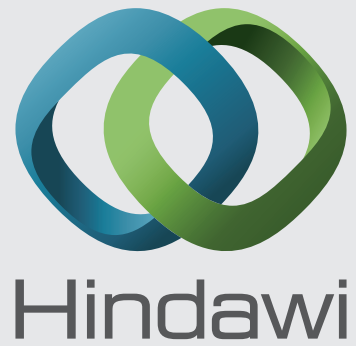

Submit your manuscripts at

http://www.hindawi.com
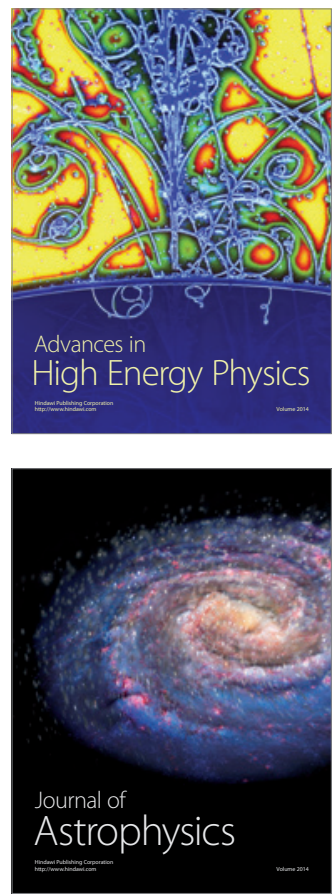
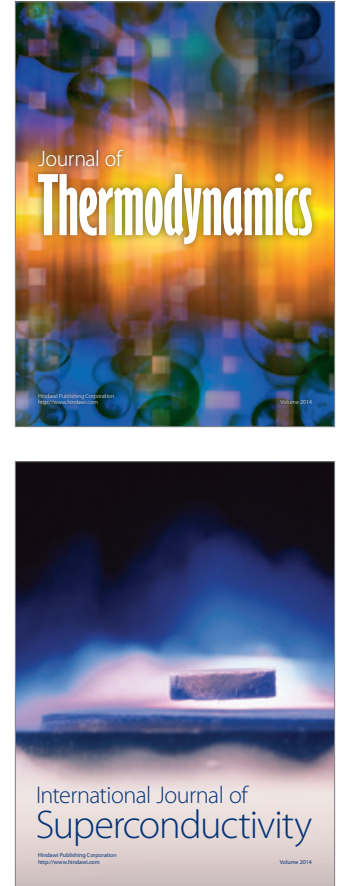
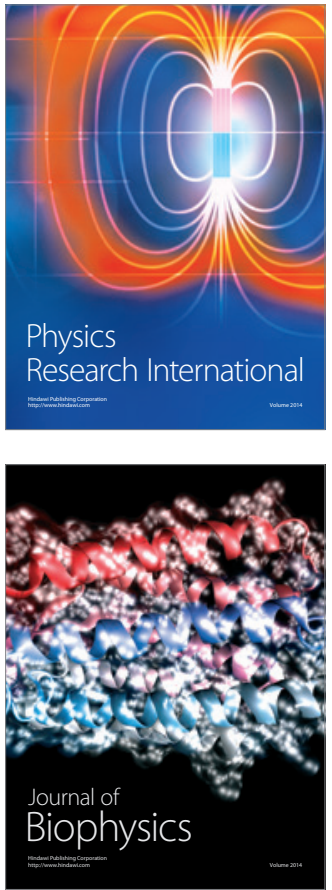
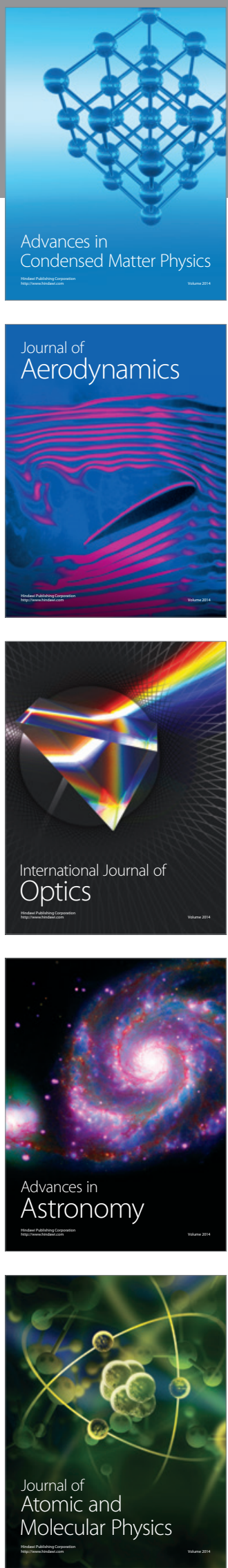